\title{
Projekt „wasserwerken“: unser Kommentar
}

Familie Musolf, Teilnehmende am Projekt „WASSERWerken“

\section{Rüdiger}

Es ist eine enorme Leistung des miraculum-Teams, ein Projekt zu entwerfen und zu ermöglichen, das dazu führt, dass Kinder und Erwachsene in ihren Sommerferien zwei Wochen lang so kreativ und intensiv an einer gemeinsamen ,großen Sache' zusammenwirken.

Der Erfolg zeigt, dass Kinder trotz aller medialer Reizüberflutung, trotz alles materiellen Überflusses bereit und in der Lage sind, sich mit zwar vielfältigen, aber letztlich ganz einfachen Gegenständen eine fantasievolle Welt zu erschaffen und dabei auch noch etwas über die Natur zu lernen.

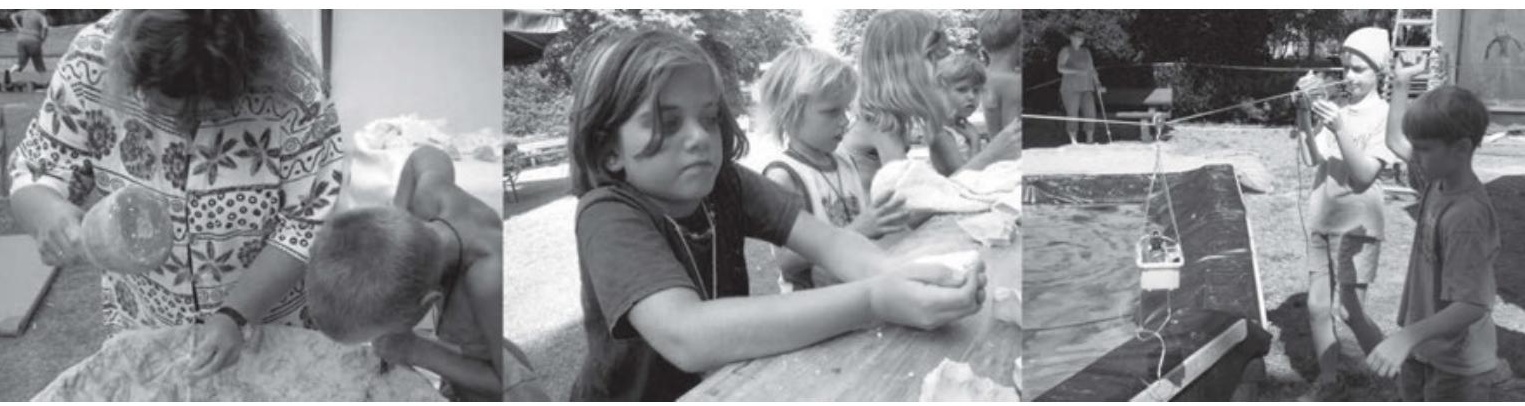

Insofern reichte dieses Projekt über das eigentliche „wasserwerken“ weit hinaus: Es bereitete den kleinen Hauptakteuren und -akteurinnen ein unvergessliches Ferienerlebnis und den Großen konnte einmal mehr demonstriert werden, wie ansteckend die Freude von Kindern sein kann, wenn sie uns aus unserem langweiligen Alltag in ihr unbeschwertes Spielen und Lernen mit hineinnehmen.

\section{Heike}

Am Anfang verstand ich meine Rolle im Projekt „wasserwerken“ der Kunstschule miraculum als die einer Chauffeurin und die des Aufsichtspersonals. Ich lernte jedoch schnell, dass ich auf dem Georgswall darüber hinaus eine große Chance geboten bekam. Ich konnte mich wieder, wie in der Kindheit, „unwichtigen“ Dingen widmen, mich in spielerisch-künstlerischem Tun verlieren, meine Kraft, Kreativität und Zeit auf ein kleines und für den Weltenlauf unwichtiges Detail richten, spielen, 
bauen und konstruieren, ohne ständig auf die Uhr zu sehen, ohne daran zu denken, was alles an Pflichten wartet.

Es war wirklich wie in meiner Grundschulzeit. Schon zu Hause planten und besprachen wir, was wir alles tun wollten: Z.B. aus einem jahrelang nur herumliegenden Fahrradreifen ein funktionierendes Wasserrad bauen, oder wir überlegten, welches Teil die große Maschine von Rainer noch interessanter machen könnte. Die Jungs planten ihre Drehtage für die filmische Reportage. Es war eine Freude zu sehen, wie sie durch die Aufgabe, Reporter zu sein, wuchsen: Fremde ansprechen, Eltern und Kinder interviewen, eigene Initiativen entwickeln, erklären und sich die Hilfe suchen, die man braucht.

Sie hatten großen Spaß und haben nebenbei eine ganze Menge gelernt; der von ihnen mit Benjamin erstellte Film ist das beste Zeugnis dafür. Vor allem haben sie auch gelernt, falsche Scheu und Scham abzulegen und vor der Kamera zielgerichtet zu agieren, dabei auch zu singen oder zu blödeln. Durch ihre besondere Aufgabe fühlten sie sich als Teil des Projektes und nutzten alle Angebote, jede/r nach seinen Vorlieben.

Der Knüller war natürlich der künstliche Teich, in dem man an den heißen Tagen so herrlich toben und plantschen konnte. Für uns als Eltern war es jeden Tag spannend zu beobachten, was die Kinder nun wieder für sich entdeckt hatten und dann selbstverständlich einsetzten. Und auch unsere Kleinste, erst drei Jahre alt, aber gar nicht schüchtern, fühlte sich mitten auf dem großen Georgswall ganz zu Hause. Ihr Strand, ihre Sonja zum Malen, ihr Bach, in dem sie spielte ... Sie scheint alle Angebote auf ihre Weise sehr intensiv genutzt zu haben und erzählt immer noch viel davon. Sie kann nur schwer verstehen, dass wir jetzt mitten im Dezember nicht die rosa Badehose anziehen und zum Georgswall baden fahren. Aber vielleicht im nächsten Jahr!

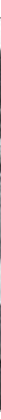




\section{Friedrich, 10 Jahre}

Ich fand die Dreharbeiten für den Film besonders toll. Ich lernte, wie man mit einer Kamera umgeht und Trickaufnahmen macht. Das Ausdenken und dann auch das Mitmachen bei den Filmtiteln machte viel Spaß. Sonst schauspielere ich nicht so gern. Außerdem war die Wasserrutsche klasse, auch wenn ich da einmal auf den Kopf geknallt bin. Aber eigentlich waren alle Stationen interessant. Wir haben sie alle durch das Filmen gut kennen gelernt.

\section{Clemens, 8 Jahre}

Ich fand am besten, dass ich gelernt habe, wie man Interviews macht. Dann fand ich noch toll, dass wir eine Kamera-Seilbahn gebaut haben. Die führte vom Werkzelt über den Teich zu Sonja hinüber. Wir machten damit mehrere Kamerafahrten. Die Bilder sehen gut aus, aber beim Zusehen wird einem schlecht vom Wackeln. Also, ich fand „wasserwerken“ einfach toll!

\section{Konstantin, 7 Jahre}

Ich habe gerne Interviews gemacht. Aber Clemens hatte immer das Mikrofon, das war nicht so schön. Das Schauspielern bei den Zwischenbildern hat mir Spaß gemacht, das war so lustig. Wir haben immer viel überlegt und probiert, bis wir etwas fertig hatten. Es war spannend, das im Film anzusehen. Ich habe auch gerne bei Ramona gemalt, aber nicht ihre Wassertierchen, sondern lieber Segelschiffe. Die Wasserrutsche war klasse!

\section{Luise, 3 Jahre}

Das Baden war schön. Und bei Sonja habe ich gemalt. Das Anmelden hat mir Spaß gemacht, da bekam ich so eine Karte umgehängt. Und mein Wasserbach war schön. Ich habe Schiffe gebaut und angemalt. Die sind auf dem Bach gefahren. (Nach Diktat von Mama aufgeschrieben) 